\title{
EVALUATION AND COMPARISON OF FOUR ONE-DIMENSIONAL UNSTEADY FLOW MODELS
}

\section{U.S. GEOLOGICAL SURVEY}

Water-Resources Investigations Report 98-4242

U.S. Department of the Interior

U.S. Geological Survey 



\section{EVALUATION AND COMPARISON OF FOUR ONE-DIMENSIONAL UNSTEADY FLOW MODELS \\ By Janice M. Fulford}

\section{U.S. GEOLOGICAL SURVEY}

Water-Resources Investigations Report 98-4242 


\section{U.S. DEPARTMENT OF THE INTERIOR \\ BRUCE BABBITT, Secretary}

U.S. GEOLOGICAL SURVEY

Charles G. Groat, Director

The use of firm, trade, and brand names in this report is for identification purposes only and does not constitute endorsement by the U.S. Geological Survey.

For additional information write to:

Chief, Deterministic Models

U.S. Geological Sunvey

Building 2101

Stennis Space Center, MS 39529
Copies of this report can be purchased from:

U.S. Geological Survey

Branch of Information Services

Box 25286

Denver, CO 80225-0286 


\section{CONTENTS}

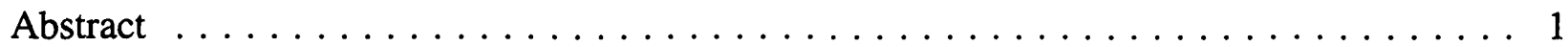

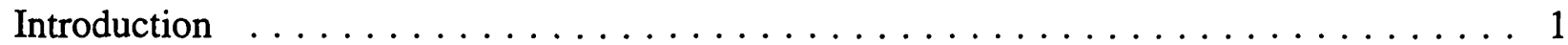

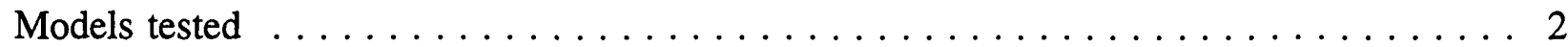

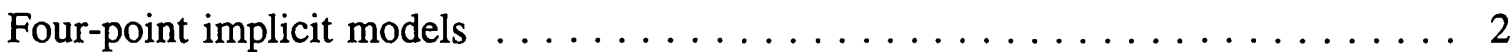

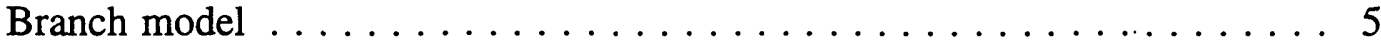

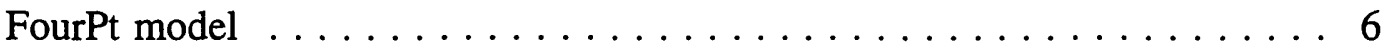

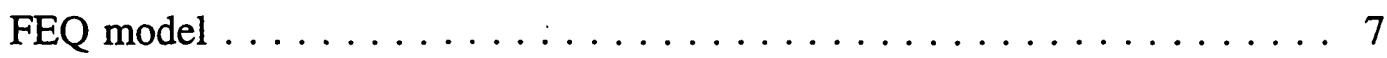

Diffusion Analogy model $\ldots \ldots \ldots \ldots \ldots \ldots \ldots \ldots \ldots \ldots$

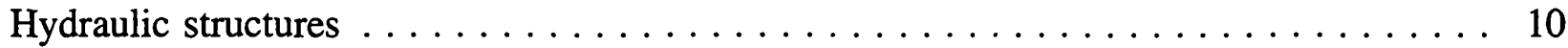

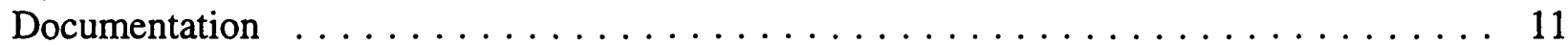

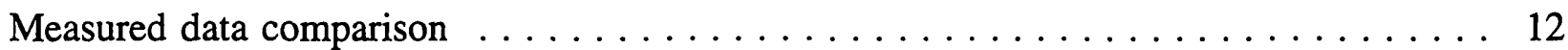

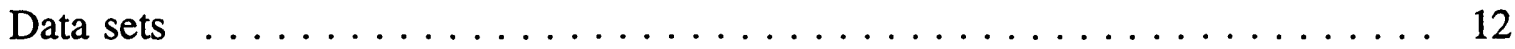

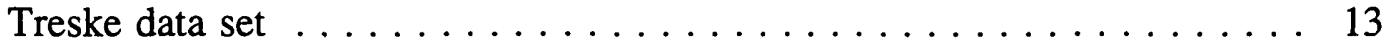

Dam-break data set ........................ 14

Sacramento River field data set $\ldots \ldots \ldots \ldots \ldots \ldots \ldots \ldots \ldots$

Results of data comparisons $\ldots \ldots \ldots \ldots \ldots \ldots \ldots \ldots \ldots \ldots \ldots \ldots$

Treske data results . . . . . . . . . . . . . . . . . . 17

Dam-break data results ..................... 20

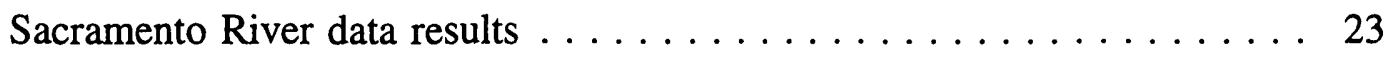

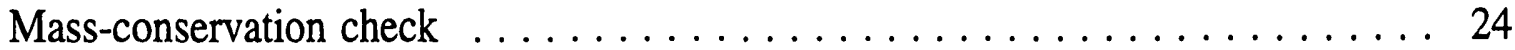

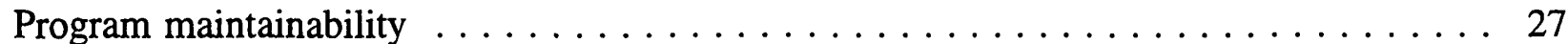

Ease of model use . . . . . . . . . . . . . . . . . . . . . . . 27

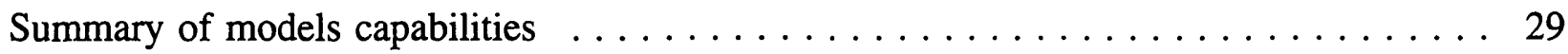

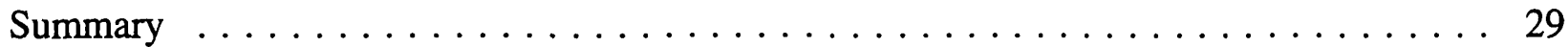

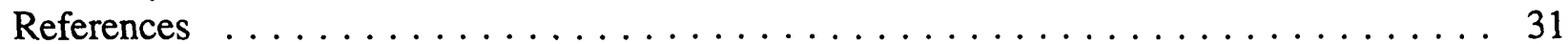

\section{FIGURES}

1. Schematic of Treske flume $\ldots \ldots \ldots \ldots \ldots \ldots \ldots \ldots \ldots \ldots \ldots$

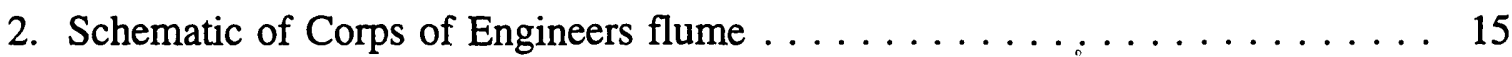

3. Sacramento River reach near Sacramento, California . . . . . . . . . . . 16

4. Results of models for Treske flume data . . . . . . . . . . . . . . 19

5. Results of models for U.S. Army Corps of Engineers flume data . . . . . . . 21

6. Results of models for U.S. Army Corps of Engineers flume data plotted with measured data at location $70 \mathrm{ft}$ upstream of outflow end ........ 22

7. Results of models for Sacramento River for October 12, 1976 data . . . . . . 24

8. Results of models for Sacramento River hydrograph of January 17, 1977 . . . 25 


\section{TABLES}

1. List of documentation for tested models $\ldots \ldots \ldots \ldots \ldots \ldots \ldots \ldots$

2. Summary of data sets used in comparison of models . . . . . . . . . . 13

3. Summary of time step and space discretizations used for each data set and model 18

4. Summary statistics of mass conservation absolute errors in percent . . . . . . 26

5. Summary of one-dimensional unsteady flow models features . . . . . . . . 30

\section{CONVERSION FACTORS}

\begin{tabular}{rcl}
\hline Multiply & By & To obtain \\
\hline & Length & \\
foot $(\mathrm{ft})$ & 0.3048 & meter \\
& Flow & \\
cubic foot per second $\left(\mathrm{ft}^{3} / \mathrm{s}\right)$ & 0.02832 & cubic meter per second \\
\hline
\end{tabular}




\title{
COMPARISON AND EVALUATION OF FOUR ONE-DIMENSIONAL UNSTEADY FLOW MODELS
}

\author{
By Janice M. Fulford
}

\begin{abstract}
Four one-dimensional unsteady flow models are compared and evaluated. Three different flow reaches were modeled and compared with measured data. Three of the models, Branch, FourPt, and FEQ, use the four-point implicit numerical scheme to solve the full dynamic flow equations. The remaining model, DaFlow, solves a kinematic version of the diffusion analogy flow equations. The FEQ and FourPt models had more robust solutions than the other two models tested. DaFlow was the easiest to use and FEQ was the most difficult. The Branch model results showed possible numerical problems with some of the simulations.
\end{abstract}

\section{INTRODUCTION}

Several one-dimensional (1-D) unsteady flow models are used by U.S. Geological Survey (USGS) personnel to simulate time-varying flow in networks of channels. This report presents a comparison and evaluation of four of the most commonly used models: Branch, DaFlow, FourPt, and FEQ.

Typical applications for 1-D unsteady models include: computation of discharge at backwater affected reaches with measured stages, delineation of flood plains, comparisons of the effects of proposed stream-system changes, and investigations into the transport of constituents. The most common application of 1-D unsteady flow models in the USGS is the computation of continuous discharge at backwater affected sites. This application far exceeds the other uses; however, it is expected that growing interest in water-quality issues will increase the number of transport investigations. Though these flow models do not solve the transport equations, they do provide the most essential variable used by the transport equations, the flow velocities throughout each reach of the stream system.

The purpose of the model comparison and evaluation is to provide information about the relative weaknesses and strengths of each model. This information will aid decision makers in allocating resources for the development and support of 1-D unsteady flow models.

The models are compared objectively by using measured data and subjectively for the ability to include hydraulic structures and controls, ease of use, and the maintainability of each model. The criteria for evaluating the models are the following, ranked in order of decreasing importance: (1) numerical robustness, (2) ability to model effects of hydraulic controls/structures, (3) maintainability of the program code, and (4) ease of use. Numerical robustness describes the ability of the program to solve for a wide range of flow conditions without instability or computational noise. Numerical robustness reflects a combination of the assumptions made in the flow equations, and the choice of numerical techniques used to solve the equations. 
Numerical robustness of the models was investigated by comparing the numerical techniques and matrix solvers used, and by using each model to simulate flows. The ability of each model to conserve mass also was investigated. Three different flow reaches were simulated with each of the four models, and the results were compared with measured data. The measured data covered a range of typical modeling applications and was used to investigate the ability of these models to simulate backwater, tidal effects, dam-break flows and flows in reaches with a main channel and an overbank section. Networks of channels were not modeled because of the lack of good measured data in networks with which to make model comparisons. No flow simulations were made to investigate the ability of the models to model hydraulic structures correctly .

Included in the following pages is a summary of the documented capabilities of each model to simulate hydraulic structures and controls, a subjective evaluation of the maintainability of program code and ease of model use. The report also includes a summary of model capabilities that may be a useful guide for model selection.

\section{MODELS TESTED}

The models tested, Branch, DaFlow, FourPt, and FEQ, all solve the time-varying flow equations for one spatial dimension. The models are capable of modeling networks. DaFlow

can simulate dendritic networks; the other models can simulate dendritic and looped networks. The models require that the flow system be idealized into a series of connected reaches. Each reach must be fairly homogeneous in regards to roughness, channel shape, and channel slope.

The models can be separated into two groups by the flow equations solved and the numerical discretization technique employed. Branch, FourPt, and FEQ all solve the full dynamic flow equations by using the four-point implicit finite-difference technique. DaFlow solves a kinematic form of the diffusion-wave analogy equation, which is a simplified form of the flow equations. This simplification prevents DaFlow from modeling backwater affected flows. DaFlow permits only upstream discharge as a boundary condition.

\section{Four-Point Implicit Models}

The four-point implicit models solve the one dimensional (1-D) equations of mass and momentum conservation. Including the effects of non-constant fluid density, the basic 1-D equations in differential form are written as,

$$
\partial \frac{\rho A}{\partial t}+\partial \frac{\rho Q}{\partial x}-\rho_{l} q=0
$$

and 


$$
\partial \frac{\rho Q}{\partial t}+\partial \frac{\left(u^{2} \rho A\right)}{\partial x}+g \partial \frac{\rho I_{1}}{\partial x}-\rho g A\left(S_{o}-S_{f}\right)+\rho g I_{2}=0
$$

where

$$
I_{1}=\int_{0}^{h}(h-y) B d y
$$

and

$$
I_{2}=\int_{0}^{h}(h-y) \frac{\partial B}{\partial x} d y
$$

where

$A$ is the cross sectional flow area,

$Q$ is the discharge,

$q$ is the lateral inflow,

$\rho$ is the density of the fluid,

$\rho_{1}$ is the density of the lateral inflow,

$u$ is the mean cross-section velocity,

$g$ is the acceleration of gravity,

$S_{o}$ is the channel slope,

$S_{f}$ is the friction slope,

$B$ is the channel top width,

$h$ is the flow depth,

$t$ is time,

$x$ is downstream reference distance, and

$y$ is the depth-integration variable.

These equations are also called the De St. Venant equations for unsteady flow. They are based on the following assumptions: (1) the flow is one dimensional, (2) pressure is hydrostatic, (3) effects of boundary friction and turbulence can be accounted by using steadystate resistance laws, (4) the channel bed slope is small, and (5) channel geometry is fixed.

Each of the four-point implicit models solve a variation of the partial-differential equations by using finite-difference techniques. For open-channel flow systems, finitedifference techniques require the division of the solution domain into a network of stream reaches. Reaches typically are flow system (or stream) segments that have homogeneous characteristics and no significant point inflows. Reaches are connected at junctions by use of 
constraining equations. Each reach is subdivided into a series of discrete nodes. Nodes are located within the reach where flow computations for the dependent variables (typically stage and discharge) will occur. Continuous derivatives at each node are then replaced by a finitedifference approximation to the derivatives. Each of the four-point models discretizes the particular equations used with the four-point implicit or Preissman technique (Cunge and others, 1980).

The four-point implicit technique can be developed by using either numerical integration on the integral form of the flow equations or by substituting finite-difference approximations into the differential forms of the flow equations. Only the difference form will be presented. The classic four-point implicit technique approximates the time derivatives of a functional value $f(J)$ with,

$$
\frac{\partial f(J)}{\partial t}=\frac{\left[\omega_{2} f_{2}^{2}+\left(1-\omega_{2}\right) f_{1}^{2}\right]-\left[\omega_{1} f_{2}^{1}+\left(1-\omega_{1}\right) f_{2}^{1}\right]}{\Delta t}
$$

when the spatial weights, $\omega_{1}$ and $\omega_{2}$, are set to 0.5 . The subscripts and superscripts on $f$, the functional value, denote space and time step, respectively. The spatial derivatives are approximated by,

$$
\frac{\partial f(J)}{\partial x}=\frac{\theta\left(f_{2}^{2}-f_{1}^{2}\right)+(1-\theta)\left(f_{2}^{1}-f_{1}^{1}\right)}{\Delta x}
$$

where $\theta$ is the time weight, which can have values between 0.5 and 1 . The non-derivative terms, such as boundary shear (or friction slope), gravity, and pressure, in the flow equations are approximated by using,

$$
f(J)=\chi f_{m}^{2}+(1-\chi) f^{1}{ }_{m}
$$

where $\chi$ is a time weight similar to $\theta$ that can have values between 0.5 and 1 , and the subscript $\mathrm{m}$ denotes a spatial average that is computed from

$$
f_{m}=\xi f_{2}+(1-\xi) f_{1}
$$

where $\xi$ is a spatial weight that typically is given a value of 0.5 . Each of the four-point implicit programs apply the above two equations to the non-derivative terms somewhat differently depending on how various terms are grouped and what weights are chosen.

The resulting matrix of finite-difference equations is a banded matrix except where flow junctions occur in the channel network. A banded matrix has non-zero elements on and around the matrix diagonals and zero elements elsewhere. The matrix terms for the junctions are located off the diagonal, producing a sparse banded matrix that can have zeros on the diagonal unless special care is taken when the matrix is constructed. Matrices with zeros on the diagonal cannot be solved by simple Gaussian elimination without using a technique called pivoting. The sparseness of the matrix makes efficient solution of the matrix 
challenging. As a result, each of the four-point implicit models uses a somewhat different strategy to solve the matrix. These differences can affect what types of problems the models are best suited to solve, ease of use, and robustness of the solution.

Channel cross-section properties for various stages or depth are needed at each node during model computations. These properties could be computed each time from the basic cross-section geometry coordinates. All the four-point implicit models tested, however, have opted to use tables of hydraulic properties tabulated by either stage or flow depth for each nodal location because the use of tabulated properties reduces the number of computations. Utility programs, specifically written for the task, are used to compute the tables. This results in model simulations that depend on the ability of the programs used to compute hydraulic properties.

The solution of the flow equations requires that boundary conditions for all open ends of the channel network must be supplied. Suitable boundary conditions are typically hydrographs of time as a function of discharge or time as a function of stage. Additionally, a boundary condition of normal depth (or water-surface slope) also is possible.

\section{Branch model}

Branch (Schaffranek and others, 1981) was developed in the mid 1970's. It is employed to compute discharges throughout the United States at sites affected by periodic backwater due to tides or manmade hydraulic structures. Branch is currently being used to simulate flow in canals in South Florida as part of the Everglades Ecosystem studies. The conservation equations solved by Branch are

$$
B \frac{\partial Z}{\partial t}+\frac{\partial Q}{\partial x}=0
$$

and

$$
\frac{1}{g A} \frac{\partial Q}{\partial t}+\frac{2 \beta Q}{g A^{2}} \frac{\partial Q}{\partial x}-\frac{\beta Q^{2}}{g A^{3}} \frac{\partial A}{\partial x}+\frac{\partial Z}{\partial x}+\frac{k \eta^{2}}{A^{2}\left(\frac{A}{B}\right)^{4 / 3}} Q|Q|-\frac{C_{D} \rho_{a}}{g \rho A} u_{a}^{2} B \cos \alpha=0
$$

where

$k$ equals 1 for units of meters and 1.49 for units of feet,

$Z$ is the water-surface elevation,

$u_{a}$ is the wind velocity,

$\rho_{a}$ is the air density,

$C_{D}$ is a drag coefficient for wind on the water surface,

$\alpha$ is the angle of the wind with the reach thalweg,

$\eta$ is a flow-resistance coefficient, 
and the remaining variables are as previously defined. This formulation includes the effect of wind and assumes density is constant throughout. Top width, B, and the flow-resistance coefficient or psuedo Manning's roughness, $\eta$, are explicitly used in the formulation. No correction is allowed for channel meanders. Solution of this equation set requires tabulated values by stage of top width, area and $\eta$, the psuedo-roughness. The utility program, CGAP (Regan, 1985), was written expressly for providing these tables for Branch. Because conveyance is not explicitly represented in the Branch formulation, the effects of any lateral variation of roughness or major breaks in cross-sectional geometry on flow resistance must be expressed by the use of composite Manning's roughness for the $\eta$ values. CGAP does not allow subsectioning of cross-sections or the computation of composite Manning's roughness. Typically, values of roughness coefficients are estimated on the basis of vegetation and sediment size and are not based on verified values. Especially in the case of cross-sectional geometry that contains overbank flood plains, conveyances computed with roughness selected in this manner without subdivision can inappropriately decrease with increasing flow depths.

The Branch model, unlike FEQ and FourPt, transforms or collapses all the equations for a reach into two transfer equations that relate the stages and flows at the two reach ends. This reduces the size of the matrix solved to order $4 \mathrm{~N}$ for a network of $\mathrm{N}$ reaches. It does not eliminate the spareness of the matrix and results in large matrices being inefficiently stored because of the large number of zeros. No effort is made to prevent the occurrence of zeros on the matrix diagonal while constructing the coefficient matrix. Gaussian elimination by using a maximum pivot strategy (Press and other, 1986) is employed to solve the matrix. This elimination technique reduces roundoff error and prevents zero divisions that would result from zeros on the matrix diagonal. It is geared to solve dense, banded matrices efficiently and is not as effective on sparse matrices.

Regan (U.S. Geological Survey, written commun., 1997) recommends that the number of nodes in a reach be limited to no more than five. This recommendation results from the adverse roundoff occurring in the solution when more than five nodes are used. The transfer equations require the computation of matrix inversions and the multiplication of inverted matrices together. As the number of matrix multiplications increases with the number of nodes (or cross-sections) within a reach, roundoff error increases. Additionally, the transfer equation formulation used does not allow flows to be distributed along a reach. Lateral inflows can only be input at junctions.

\section{FourPt model}

FourPt (DeLong and others, 1997) was developed in the late 1980's as a training tool for modelers. It was selected by the State of California, Department of Water Resources, after their evaluation of several models, for use in developing an integrated modeling system for the complex Sacramento River Delta. The model has also been used to simulate rivers in Idaho and Puerto Rico.

The conservation equations solved by FourPt are 


$$
\frac{\partial}{\partial t}\left(\rho M_{a} A\right)+\frac{\partial}{\partial x}(\rho Q)-\rho_{l} q=0
$$

and

$$
\frac{\partial}{\partial t}\left(\rho M_{q} Q\right)+\frac{\partial}{\partial x}\left(\beta \rho \frac{Q^{2}}{A}\right)+g A\left(\rho \frac{\partial Z}{\partial x}+\rho \frac{Q|Q|}{K^{2}}+\frac{\partial \rho}{\partial x} \bar{z}\right)=0,
$$

where

$\bar{z}$ is the distance from the water surface to the centroid of the cross section and $M_{a}$ and $M_{q}$ are sinuousity coefficients.

This formulation includes the effect of varying density and sinuousity coefficients to correct for the volumetric effects of channel meanders (Delong, 1986); it does not include wind effects. Solution of this equation set requires tabulated values by depth of conveyance, area, momentum coefficient, area-weighted sinuosity, flow-weighted sinuosity, width, and wetted perimeter. The program, HYDIE (Fulford, 1993), was written to provide these tables for natural channels, such as those with flood plains that may require subdivision for appropriate computations of conveyance. Specifically compiled versions of FourPt can be used for stream networks that have reaches of either trapezoidal or rectangular shape.

The resulting matrix is solved by using Gaussian elimination without any pivoting. Because no pivoting is done on the matrix, the junction equations are loaded so that no zeros are located on the matrix diagonal. To efficiently store and compute the matrix, FourPt stores the two-dimensional sparse matrix as a one-dimensional array containing only non-zero elements. Gaussian elimination is performed by using the one-dimensional array. This technique is sometimes called a skyline solver, due to the resemblance of the matrix with off diagonal elements to a skyline. The matrix solution technique does not require any particular set or order of the boundary conditions in the user-built data input file. The program determines from the boundary condition type how to place the equations at junctions or open boundaries in the solution matrix appropriately.

\section{FEQ model}

FEQ (Franz and Melching, 1997a) was developed in the 1970's by Delbert Franz, an engineering consultant with Linsley Kraeger Associates. The model is in the public domain and has been used by State and local agencies, the USGS, and by the South Florida Water Management District.

The conservation equations in the differential form that are solved by FEQ are 


$$
\frac{\partial}{\partial t}\left(M_{d} A\right)+\frac{\partial Q}{\partial x}-q=0
$$

and

$$
\frac{\partial}{\partial t}\left(M_{q} Q\right)+\frac{\partial}{\partial x}\left(\beta \frac{Q^{2}}{A}\right)+g A\left[\partial \frac{Z}{\partial x}+\frac{Q|Q|}{K^{2}}\right]+\frac{C_{D} \rho_{a}}{\rho} u_{a}^{2} B \cos \alpha=0
$$

This formulation includes the effect of wind and corrections for the volumetric effects of meanders. Solution of the equation set requires, at a minimum, tabulated values of depth, top width, area, square root of conveyance, and momentum coefficient. The program, FEQUTL (Franz and Melching, 1997b), was written to provide the tables needed by FEQ and permits subdivision of cross-sections to allow appropriate computations of conveyance for channels with flood plains or lateral variation of roughness.

FEQ solves the matrix by using an $\mathrm{L} \mathrm{U}$ decomposition technique. The technique is a direct method that is based on Crout's variant of Gaussian elimination (Press and others, 1986). Because no pivoting is employed, the matrix is constructed to prevent most zeros from occurring on the diagonal. If zeros do occur on the matrix diagonal, users are required to reorder the network description to move the zero off the diagonal (Franz and Ishii, 1998). The matrix construction technique cannot be applied if all upstream boundaries are a function of stage, thus flow must be specified at a minimum of one upstream boundary. For cases without flow specified at an upstream boundary, a dummy reach with a zero flow into the network must be added so that the matrix can be constructed. Flow must be specified as the first boundary condition in the input data file at the user designated upstream end of a reach.

\section{Diffusion Analogy Model}

DaFlow (Jobson, 1989) was developed in the 1970's. It is employed primarily in conjunction with transport modeling studies.

DaFlow solves a simplified version of the basic flow equations. It uses an empirical relationship between cross-sectional area and normal discharge that was developed for flows that are less than or equal to bankfull flow. The relationship, which is based on geomorphic information (Leopold and others, 1964), is

$$
A=a_{0}+a_{1} \bar{Q}^{a_{2}}
$$

where

$\bar{Q}$ is the normal discharge,

$a_{0}$ is the average cross-sectional area at zero flow, and 
$a_{1}$ and $a_{2}$ are hydraulic geometry coefficients.

This relationship implies that a single-valued relationship exists between discharge and crosssectional area. When substituted into the diffusion form of the flow equation it yields,

$$
\frac{\partial \bar{Q}}{\partial t}+C \frac{\partial \bar{Q}}{\partial x}-D \frac{\partial^{2} \bar{Q}}{\partial x^{2}}=0
$$

where

$C$ is the wave speed, and

$D$ is the dispersion coefficient.

Both the wave speed and the dispersion coefficient are computed by using empirically based equations. The wave speed is derived from the empirical relationship between area and discharge,

$$
C=\frac{Q^{\left(1.0-a_{2}\right)}}{a_{1} a_{2}}
$$

The dispersion coefficient is computed from,

$$
D=\frac{Q_{R}}{2 S_{0} B}
$$

where

$Q_{R}$ is a representative discharge, and

$B$ is the channel top width.

The channel top width is computed from the empirical function,

$$
B=b_{1} \bar{Q}^{b_{2}}
$$

where

$b_{1}$ and $b_{2}$ are width coefficients.

The final form of the flow equation that is solved by DaFlow functions like a modified form of the kinematic wave equation of the form,

$$
\frac{\partial Q}{\partial t}+\left(C \pm D_{u}\right) \frac{\partial Q}{\partial x}=0
$$

where

$$
D_{u} \text { is a diffusion speed. }
$$


The kinematic wave equation requires only one boundary condition for solution and ignores inertia and pressure forces. In comparison, the diffusion form (eq. 16) requires two boundary conditions. Thus, the equation used by DAFLOW is frequently referred to as the diffusionanalogy method.

The formulation used by DaFlow cannot account for backwater effects because it assumes single-valued relations between area and discharge. Flow networks that have tidal or significant backwater effects cannot be modeled using this formulation.

Solution of this equation set requires values of the dispersion coefficient, the area coefficients $\left(a_{0}, a_{1}\right.$ and $\left.a_{2}\right)$ and the top width coefficients $\left(b_{1}\right.$ and $\left.b_{2}\right)$ for each cross section. The area and top width coefficients can be estimated from wave travel times and top widths for peak flows of two different sizes or from flow resistance coefficients and channel width. The program, CEL (Jobson, 1989), is provided with the DaFlow program to compute these coefficients. The area and width equation used can only fit channels in which top width changes smoothly with flow depth and thus is not applicable for reaches that have wide flood plains in relation to the main channel.

A mode splitting technique is used in DaFlow to solve for flow. The advective and dispersive portions of the flow are solved in separate steps. The dispersive portion is solved by using a Lagrangian reference frame and modifies the wave heights. After the dispersive step, the waves are advected or translated at the wave speed of each wave. A flow or discharge boundary condition, which is located at the unconnected upstream ends of each reach, is required for solution. Additionally, tributary inflows can be added to any reach node. No downstream boundary condition is used in the model in contrast to models solving the full dynamic equations.

\section{HYDRAULIC STRUCTURES}

The programs tested, except for DaFlow, allow the representation of hydraulic structures or flow controls in the stream network. The four-point implicit programs tested include structures, primarily through the use of tables of water-surface elevations and discharge that describe the flow behavior of the structure. These tables are produced by using 1-D steady state flow programs such as the Water-Surface Profile program, WSPRO (Shearman, 1990), for bridge openings; the Culvert Analysis Program, CAP (Fulford, 1995), for culverts; or the Full Equations Utility program, FEQUTL (Franz and Melching, 1997b), for many other types of structures. These tables can also be constructed from field measurements.

FEQ also has several hydraulic structure types that are coded as functions in the program, such as variable height weirs and gates. Additionally, FEQ allows operation rules that are a function of flow at selected points in the stream network to be applied to hydraulic structures, such as gates and pumps. Branch allows the effects of hydraulic structures (Sanders, 1995), such as gates, on the flow system to vary with time by using a multiplier. FourPt does not allow the effects of hydraulic structures to vary with time. 


\section{DOCUMENTATION}

All models have documentation available (table 1) that describe the equations solved and the numerical techniques used. Branch, DaFlow, FourPt, and FEQ have published documentation.

Branch documentation is well organized, brief, and functional. It provides all the basic information needed to run the model for a single branch. Unfortunately, it does not contain a

Table 1. List of documentation for tested models [WRIR, Water Resources Investigations Report; HASS, U.S. Geological Survey Hydrologic Analysis Software Support]

\begin{tabular}{|c|c|}
\hline Models & Available Documentation \\
\hline DaFlow & $\begin{array}{l}\text { Jobson, H.E., 1989, U.S. Geological Survey WRIR 89-4133, User's } \\
\text { Manual For An Open-Channel Stream Flow Model Based on the } \\
\text { Diffusion Analogy }\end{array}$ \\
\hline Branch & $\begin{array}{l}\text { Schaffranek, R.W., Baltzer, R.A., and Goldberg, D.E., 1981, U.S. } \\
\text { Geological Survey TWRI Chapter C3, Book 7, A Model for } \\
\text { Simulation of Flow in Singular and Interconnected Channels } \\
\text { Regan, R.S. and Schaffranek, 1992, unpublished notes distributed } \\
\text { with program by HASS, Summary of Enhancements and Additions to } \\
\text { the Branch-Network (BRANCH) Dynamic Flow Models }\end{array}$ \\
\hline FourPt & $\begin{array}{l}\text { DeLong, L.L., Thompson, D.B. and Lee, J.K., 1997, WRIR 97-4016, } \\
\text { The Computer Program FourPt (Version 95.01)- A Model for } \\
\text { Simulating One-Dimensional, Unsteady, Open-Channel Flow }\end{array}$ \\
\hline FEQ & $\begin{array}{l}\text { Franz, D.D., and Melching, C.S., 1997, WRIR 96-4240, Full } \\
\text { Equations (FEQ) Model for the Solution of the Full, Dynamic } \\
\text { Equations of Motion for One-Dimensional Unsteady Flow in Open } \\
\text { Channels and through Control Structures } \\
\text { Franz, D.D., and Melching, C.S., 1997, WRIR 97-4037, Full } \\
\text { Equations Utilities (FEQUTL) Model for the Approximation of } \\
\text { Hydraulic Characteristics of Open Channels and Control Structures } \\
\text { During Unsteady Flow } \\
\text { Franz, D.D., and Ishii, A., 1997, User's Guide for the Full-Equations } \\
\text { (FEQ) Model of One-Dimensional, Unsteady, Open-Channel Flow, } \\
\text { on file with U.S. Geological Survey at Urbana, IL } 61801\end{array}$ \\
\hline
\end{tabular}


well explained or illustrated example on how the input is constructed for networked channels. Numerous enhancements and corrections have been made to Branch since publication of the original documentation. Only brief unpublished notes on the enhancements are available and some features, such as the inclusion of hydraulic structures, are not explained adequately.

FourPt documentation is terse. However, sufficient information and examples are available in the documentation to allow a user to run the model successfully. Information is presented on how to include hydraulic controls, build channel networks, and add new routines for hydraulic controls.

FEQ documentation is very lengthy and complete. The primary FEQ document (Franz and Melching, 1997a) does not provide enough information for a novice FEQ user with 1-D modeling experience to run the model. The user's guide (Franz and Ishii, 1997) is necessary to determine how to construct input files for FEQ and provides excellent help on how to run the model.

DaFlow documentation is sufficient to guide a user in successful operation of the model. The documentation is terse, but it includes examples that illustrate the use of the model. Unfortunately, some of the basic calculations used in DaFlow are presented in the example and appendix sections. The actual equations used for wave speed and dispersion coefficients would have been better presented in the either the section on the diffusion analogy or the solutions procedure. The solution procedure is presented heuristically. A more mathematically rigorous explanation that includes difference forms of the equations solved would make the details of the solution procedure clearer.

\section{MEASURED DATA COMPARISON}

One-dimensional unsteady flow models may be expected to model accurately the effects of tide and backwater, reaches with overbank or flood plain sections and abrupt flows, such as dambreaks throughout a stream network. Unfortunately, there are very few good complete data sets of careful measurements for testing numerical flow models. No carefully measured data sets for streamflow networks are available. As a result, the network capabilities of the models were not directly tested and only single reaches were modeled. Another shortcoming of available data sets is the general lack of measurements made of either flow or watersurface elevations at locations other than the boundaries. This forces comparisons of model results to measurements located at the boundary conditions, which is the location at which the model is directly constrained by measured data. Thus, comparisons of model results with boundary condition measurements are likely to give an indication of better model performance than actually exists.

\section{Data Sets}

The three data sets used for model comparison cover a range of flow conditions that are commonly encountered in flow modeling of river systems. Each of the data sets is a simple reach with two open boundaries. All sets have measured data for comparison of the model 
solutions. The data sets are: (1) Treske flume data (Canadian Society of Civil Engineers, written commun., 1993); (2) U.S. Army Corps of Engineers (COE) dam-break flume data (Schmidgall and Strange, 1961); and (3) Sacramento River field data (Schaffranek and others, 1981). A summary of the three data sets used is listed in table 2.

No effort was made during testing to "calibrate" models. Models are calibrated by appropriate selection of model parameters, such as roughness coefficients or dispersion coefficients. Typically, model parameters are selected (or the model calibrated) by iteratively adjusting the model parameters until model results match the measured flow and watersurface elevations for the flow system, and a particular set of boundary conditions. The data sets used for the model comparisons included roughness values that were determined from steady-state flow conditions or other means, so that calibration was not needed. Models were run and compared by using the same parameters whenever possible.

Table 2. Summary of data sets used in comparison of models [ $\mathrm{ft}$, feet; boundary, type of boundary conditions used in model runs]

\begin{tabular}{|l|c|c|c|}
\hline \multicolumn{1}{|c|}{ Data set } & Treske flume & COE flume & Sacramento River \\
\hline \hline Flow effects & overbanks & dambreak & tidal/back water \\
\hline Upstream boundary & discharge & discharge & stage \\
\hline Downstream boundary & stage & stage & stage \\
\hline Reach length (ft) & 689 & 125 & 57,024 \\
\hline Channel width (ft) & 18.86 & 4.0 & 600. \\
\hline Channel slope & 0.00019 & 0.005 & $6.0 \times 10^{-7}$ \\
\hline Duration (seconds) & 12,960 & 240 & 27,900 \\
\hline
\end{tabular}

\section{Treske data set}

The Treske flume data are for a laboratory flume with overbank sections. The channel cross section has a low-water channel that is 4.1 feet $(\mathrm{ft})$ wide by $1.28 \mathrm{ft}$ deep. The left overbank is $9.84 \mathrm{ft}$ wide and the right overbank is $4.92 \mathrm{ft}$ wide. The portion of the flume reach that was modeled is $689 \mathrm{ft}$ long and has a slope of 0.00019 . Figure 1 illustrates the dimensions of the Treske flume. A Manning's roughness coefficient of 0.012 was estimated for the flume from uniform-flow experiments. Total duration of the hydrograph is 216 minutes. Peak discharge is 14.5 cubic feet per second $\left(\mathrm{ft}^{3} / \mathrm{s}\right)$. Initial and final discharges are 3.39 and $3.46 \mathrm{ft}^{3} / \mathrm{s}$, respectively. Measured upstream discharges and downstream stages were used for boundary conditions in Branch, FourPt, and FEQ. Only upstream discharges were 


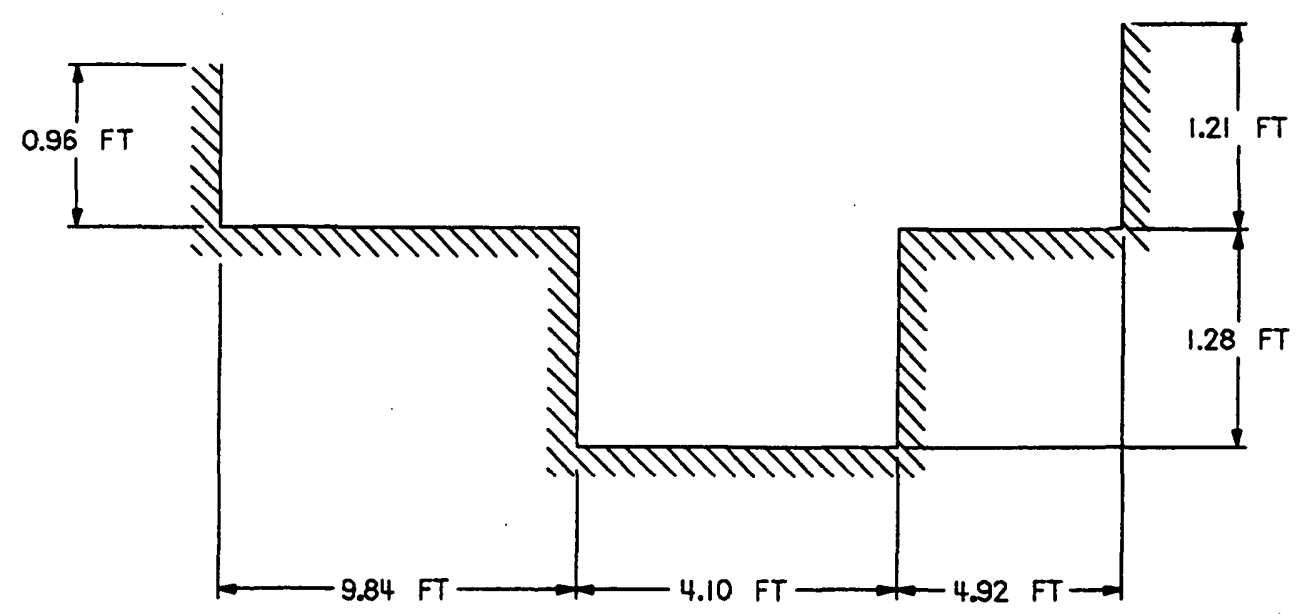

A.

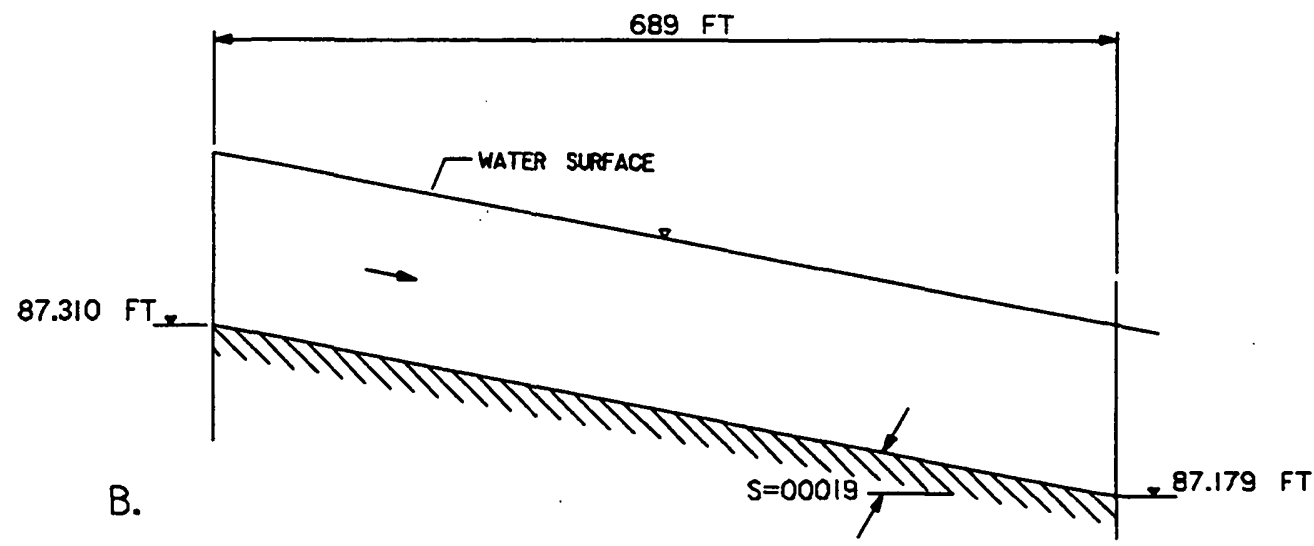

Figure 1. Schematic of Treske flume showing (A.) flume cross section, and (B.) longitudinal section.

used in DaFlow as boundary conditions. Measured upstream stages and downstream discharges were compared with model results.

\section{Dam-break data set}

The COE dam-break data are for a laboratory flume with a 4-ft wide rectangular section and a slope of 0.005 . The experiment simulated the sudden failure of a dam retaining a pool of water. A base-flow depth of $0.57 \mathrm{ft}$ was the initial condition downstream of the dam before failure. A $125-\mathrm{ft}$ reach immediately downstream of the dam was modeled. The 


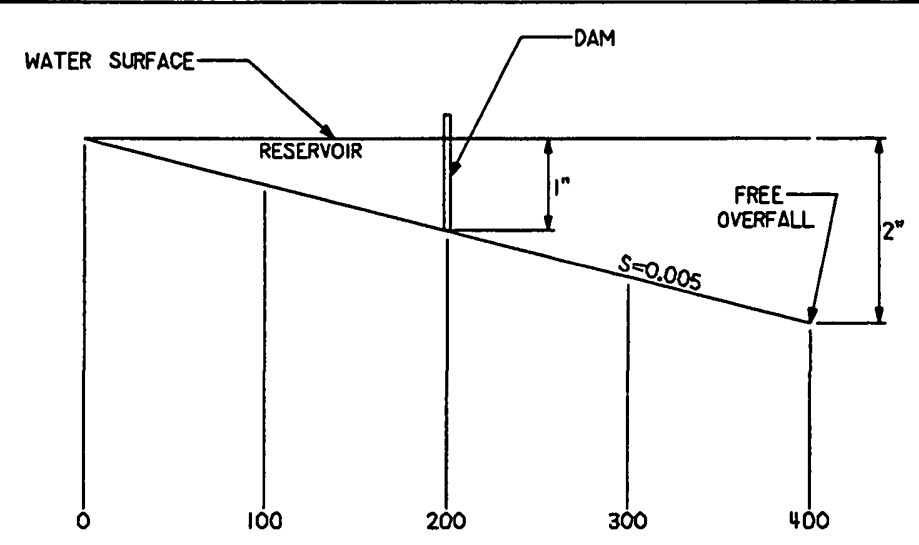

A.

STATIONS ALONG FLUME, FT

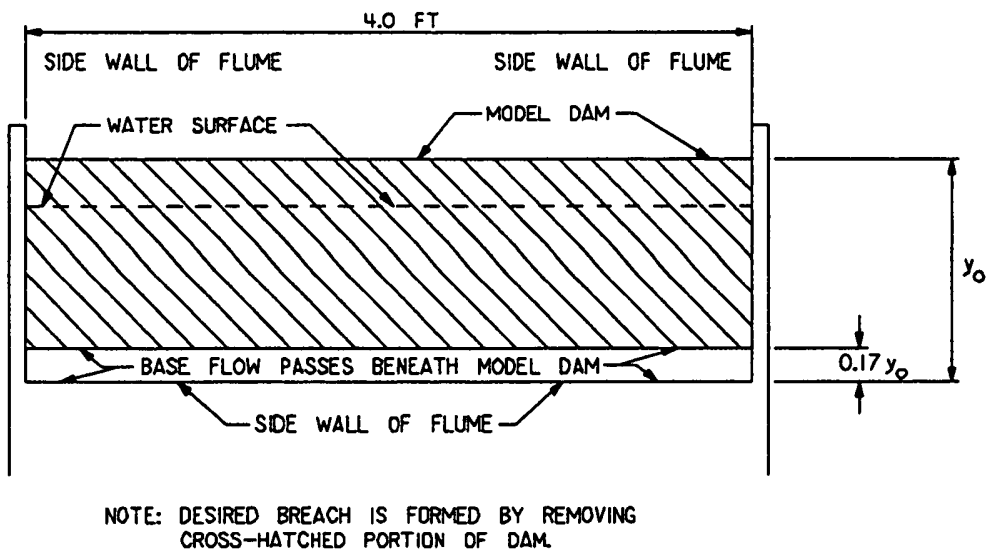

B.

Figure 2. Schematic of Corps of Engineers flume showing (A.) longitudinal section, and (B.) flume cross section near dam location.

inch by 0.75 -inch aluminum angles that were installed with one leg tacked to the flume floor perpendicular to the flow at 0.5 -foot intervals. Manning's roughness coefficients from uniform flow experiments were estimated to be 0.04 at $0.7-\mathrm{ft}$ flow depth and 0.12 at 0.15 -ft flow depth. Total duration of the hydrograph is 240 seconds with a peak discharge of 5.24 $\mathrm{ft}^{3} / \mathrm{s}$ and a base flow of $3.31 \mathrm{ft}^{3} / \mathrm{s}$. Upstream discharges were used in DaFlow as the boundary condition. Measured upstream discharges and downstream stages were used for boundary conditions in Branch, FourPt, and FEQ. Measured upstream stages, downstream discharges, measured stages and discharges located $70 \mathrm{ft}$ from the downstream boundary were compared with model results. 


\section{Sacramento River field data set}

The Sacramento River field data are for a reach between USGS streamflow-gaging stations 11447500 at Sacramento and 11447650 near Freeport, California. The reach is 10.8 miles in length and is affected by tides. No measured station and elevation data were available for the reach. Trapezoidal cross-section geometry data for two cross sections were synthesized from the geometry tables that contain stage and area presented in Schaffranek and others (1981). A schematic of the reach modeled is shown in figure 3. Manning's

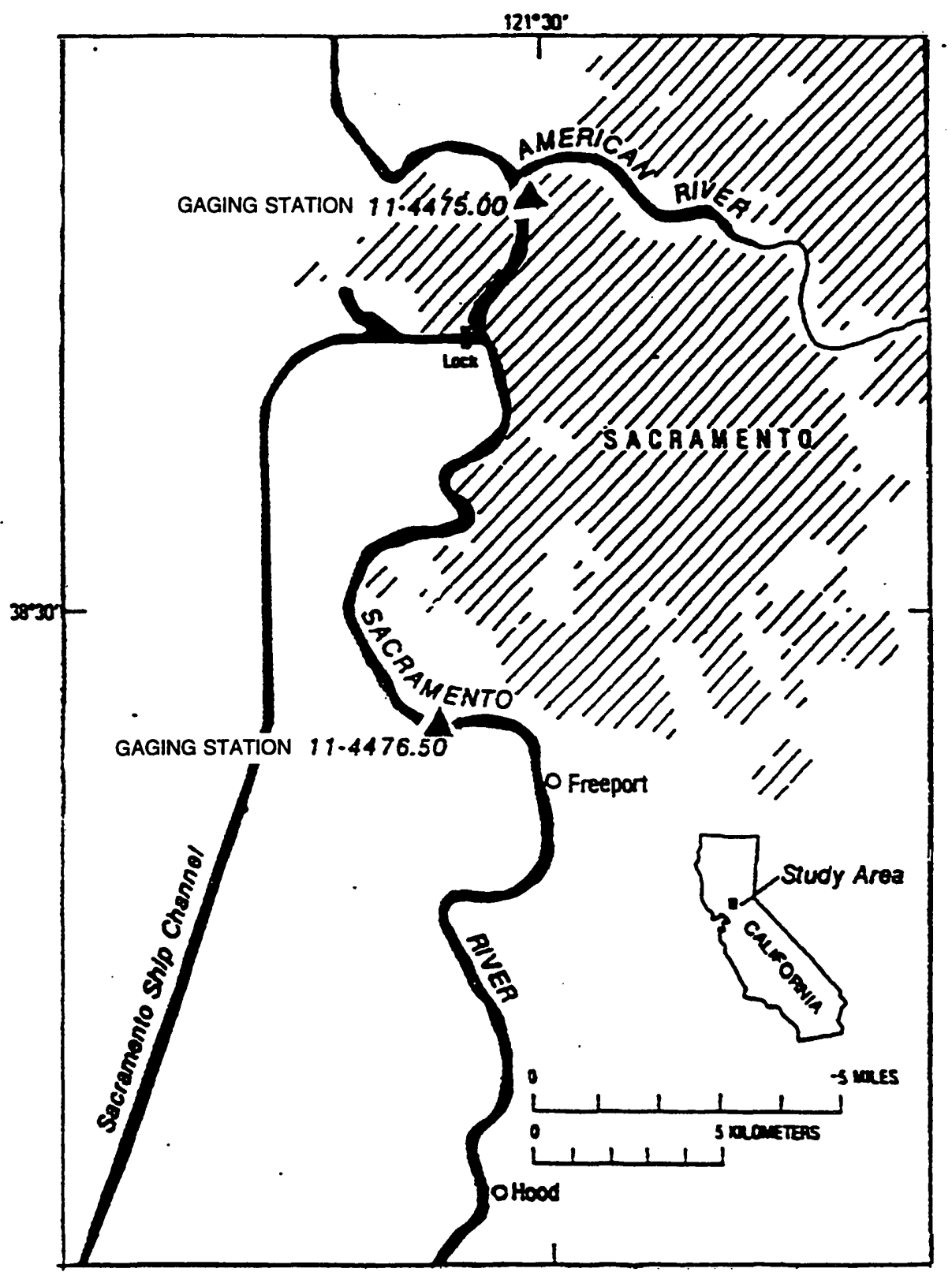

Figure 3. Sacramento River reach near Sacramento, California 
roughness coefficient used in the model simulations is 0.02623 (Schaffranek and others, 1981). Two hydrographs were simulated, but only one hydrograph had measured data available for comparison. The first hydrograph, with measured discharge data at the upstream end, has a duration of 465 minutes with a peak discharge of $8780 \mathrm{ft}^{3} / \mathrm{s}$. The duration does not cover an entire tidal cycle. The second hydrograph is for the 24-hour period of January 17 , 1977. Stage data for the boundary conditions were digitized from figure 1 in Schaffranek and others (1981). No measured discharges were available for these data. Measured stages at the open boundaries were used for the boundary conditions in Branch, FourPt, and FEQ.

\section{Results of Data Comparisons}

Attempts were made to run all models with similar parameters and data, such as same number of cross sections and same weighing coefficients. Hydraulic-property tables were constructed by using either the HYDIE or FEQUTL programs. The HYDIE program was used to compute the geometry tables for both Branch and FourPt. The FEQUTL program was used for FEQ. DaFlow uses exponential relationships of width and area with discharge that are determined from either roughness values or lagtimes. The CEL program that is distributed with DaFlow was used to compute the needed coefficients for the exponential relationships. The various time step and space discretizations used for each data set are summarized in table 3. DaFlow does not output stages at the upstream or downstream end of a model reach and was not compared to measured stages.

\section{Treske data results}

The Treske data was simulated with several different time-step sizes and space discretizations (table 3). This data set is challenging because the flow rises into and out of the overbank areas of the cross section at a flow depth of $1.28 \mathrm{ft}$. When flow first enters or exits the overbank area a large change in channel width and wetted perimeter occurs that invalidates the use of Manning's equation for roughness effects unless either cross-section subsectioning (Davidian, 1984) or a composite roughness value that varies with depth is used. Subsectioning is required because of shape and not because of a horizontal change in roughness in material. Additionally, the numeric techniques used do not work well when an abrupt change occurs in a function, such as top width in relation to depth.

All models ran the data successfully. Branch, FourPt, and FEQ ran all time step and space discretizations attempted. Reasonable fits of the peak discharge at the downstream boundary were computed by all models. DaFlow overestimated the peak slightly in comparison with the four-point implicit models. The results for a 3-minute time step with a $172.25 \mathrm{ft}$ space discretization are shown in figure 4.

DaFlow results do not match the subtleties of the discharge hydrograph shape as well as the four-point implicit models. Because of the equation that DaFlow uses to represent area, it is not able to account for the rapid change in wetted perimeter. This results in a slightly larger peak discharge that arrives somewhat ahead of the actual peak arrival time. 
Table 3. Summary of time step and space discretizations used for each data set and model [ $\Delta x$, spatial discretization; $\Delta t$, time step; $\mathrm{ft}$, feet; sec, seconds; $\mathrm{n} / \mathrm{a}$, not applied; $\mathrm{X}$, model ran; $\mathrm{R}$., river]

\begin{tabular}{|c|c|r|c|c|c|c|}
\hline \multirow{2}{*}{ DATA SET } & \multirow{2}{*}{$\begin{array}{c}\Delta \mathrm{x} \\
(\mathrm{ft})\end{array}$} & \multirow{2}{*}{$\begin{array}{c}\Delta \mathrm{t} \\
(\mathrm{sec})\end{array}$} & \multicolumn{4}{|c|}{ Model } \\
\cline { 5 - 8 } & & & DaFlow & Branch & FourPt & $\mathrm{FEQ}$ \\
\hline \hline Treske Flume & 689.0 & 360 & $\mathrm{X}$ & $\mathrm{X}$ & $\mathrm{X}$ & $\mathrm{X}$ \\
\hline & 689.0 & 180 & $\mathrm{n} / \mathrm{a}$ & $\mathrm{X}$ & $\mathrm{X}$ & $\mathrm{X}$ \\
\hline & 172.25 & 180 & $\mathrm{X}$ & $\mathrm{X}$ & $\mathrm{X}$ & $\mathrm{X}$ \\
\hline & 53.0 & 60 & $\mathrm{n} / \mathrm{a}$ & $\mathrm{X}$ & $\mathrm{X}$ & $\mathrm{X}$ \\
\hline COE Dam Break & 125.0 & 1 & $\mathrm{n} / \mathrm{a}$ & $\mathrm{X}$ & $\mathrm{X}$ & $\mathrm{X}$ \\
\hline & 25.0 & 1 & $\mathrm{X}$ & $\mathrm{X}$ & $\mathrm{X}$ & $\mathrm{X}$ \\
\hline & 5.0 & 1 & $\mathrm{X}$ & $\mathrm{X}$ & $\mathrm{X}$ & $\mathrm{X}$ \\
\hline Sacramento River & 28512.0 & 900 & $\mathrm{n} / \mathrm{a}$ & $\mathrm{X}$ & $\mathrm{X}$ & $\mathrm{X}$ \\
\hline
\end{tabular}

"DaFlow was not applied because it cannot model backwater effects.

The four-point implicit models use tables of hydraulic properties that can be constructed to bracket the rapid expansion of the wetted perimeter. This helps these models match the hydrograph subtleties but also provides a source of error. Oscillations occur in the simulated discharge hydrograph at the downstream end (figure $4 \mathrm{~b}$ ) when the flow enters and exits the overbank areas.

When the water-surface elevations equal or exceed the bottom elevation of the overbanks, Branch has the largest oscillations among the four-point implicit models. It is likely that Branch has the largest oscillations because it does not easily allow conveyance to vary as smoothly as do FEQ and FourPt. The Branch equation formulation computes conveyance from a roughness coefficient explicitly expressed in the equations solved. Because of the channel shape, the Branch formulation will erroneously compute a decrease in conveyance as depth increases if a constant roughness coefficient is used. FEQ and FourPt use tabulated values of conveyance that can resolve the effect of rapid wetted-perimeter changes on roughness effects, if roughness and shape variations are accounted for when the hydraulic property tables are computed. For Branch to resolve the effect of the rapid increase in wetted perimeter, a composite roughness that varies with depth is needed. Branch allows roughness coefficients to vary with depth; however, composite roughnesses for a range of depths would need to be computed by using a subdivided cross section. Branch's hydraulic property 

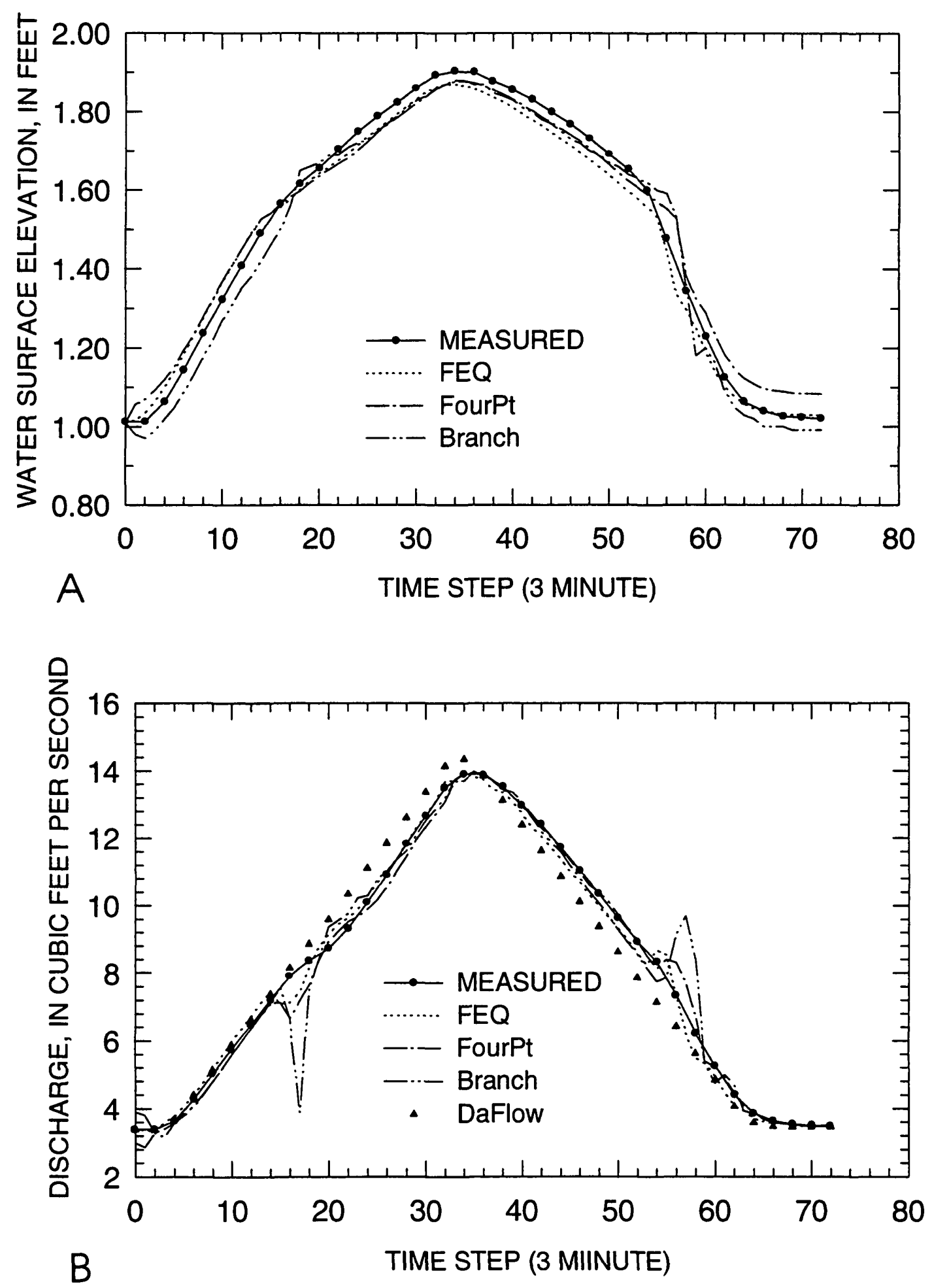

Figure 4. Results of models for Treske flume data plotted with measured data; a) upstream end, b) downstream end of reach for a 3-minute time step and $172.25 \mathrm{ft}$ spatial discretization. 
routine, CGAP, does not allow for subdivision of cross-sectional area and the computation of a composite roughness. It is expected that typical users of Branch would use CGAP for constructing hydraulic property tables and no effort was made to compute composite roughnesses for the Branch model to use.

\section{Dam-break data results}

The COE dam-break data were simulated with 1-second time steps and several space discretizations. All models except for Branch allowed the use of time steps smaller than a minute and boundary conditions collected at less than a minute interval. The Branch source code was modified to run with second- or minute-sized time steps and boundary conditions collected at second or minute intervals for the purpose of this test. The results from the modified code were compared with the results of the unmodified code and no differences were found for the one-minute interval data.

Preliminary runs of the models did not match measured data closely. Branch, FourPt, and FEQ overestimated the downstream stage when the flow approached steady-state conditions indicating a possible problem with the roughness parameters used. Roughness parameters were recomputed assuming that the flow depth below the tops of the 0.75 -inch high aluminum angle legs on the flume floor did not contribute to the flow. Boundary inflows also were recomputed to account for the dead-flow zone below the tops of the angles. Correction of the roughness data resulted in computed roughness values of 0.040 at a flow depth of $0.26 \mathrm{ft}$ and 0.037 at a flow depth of $0.50 \mathrm{ft}$.

Plots of measured data and model results for a length discretization of $5 \mathrm{ft}$ and a time step of 1 second are shown in figures 5 and 6 . None of the models matched closely the peakdischarge hydrograph shape for any of the simulations. Both FEQ and FourPt, however, matched stages closely at the upstream end (fig. 5B) and at the location in the middle of the reach (fig. 6B). For this time step and spatial discretization, FEQ and FourPt results nearly match each other during the peak rise and recession.

Branch was run with multiple reaches that had no more than 5 cross sections in a reach. The Branch simulated discharge hydrographs for the 5-foot space discretization and 1-second time step had an unrealistic rise in discharge occuring prior to the arrival of the measured peak at the downstream end and middle reach locations (figs. 5A and 6A). Neither FourPt or FEQ display this feature in their respective discharge hydrographs. Branch also consistently underestimated by about $0.04 \mathrm{ft}$ the peak and steady-flow stages for the reach. In an effort to determine the source of the stage difference, roughness values and cross-section property tables for Branch were checked for errors. Roughness values were found to be correct; however, cross-section property tables for Branch were found to have few significant figures. Unfortunately, new tables that contain more significant figures did not result in any improvement in the Branch results. Because the flow areas are small, it is possible that an unknown source of roundoff error in Branch may be producing this difference. For typical natural reaches, this stage difference would be very small. The stairstepping of the Branch stage hydrographs (figs. 5B and 5A) is due to model results being output to hundreths of a foot. 

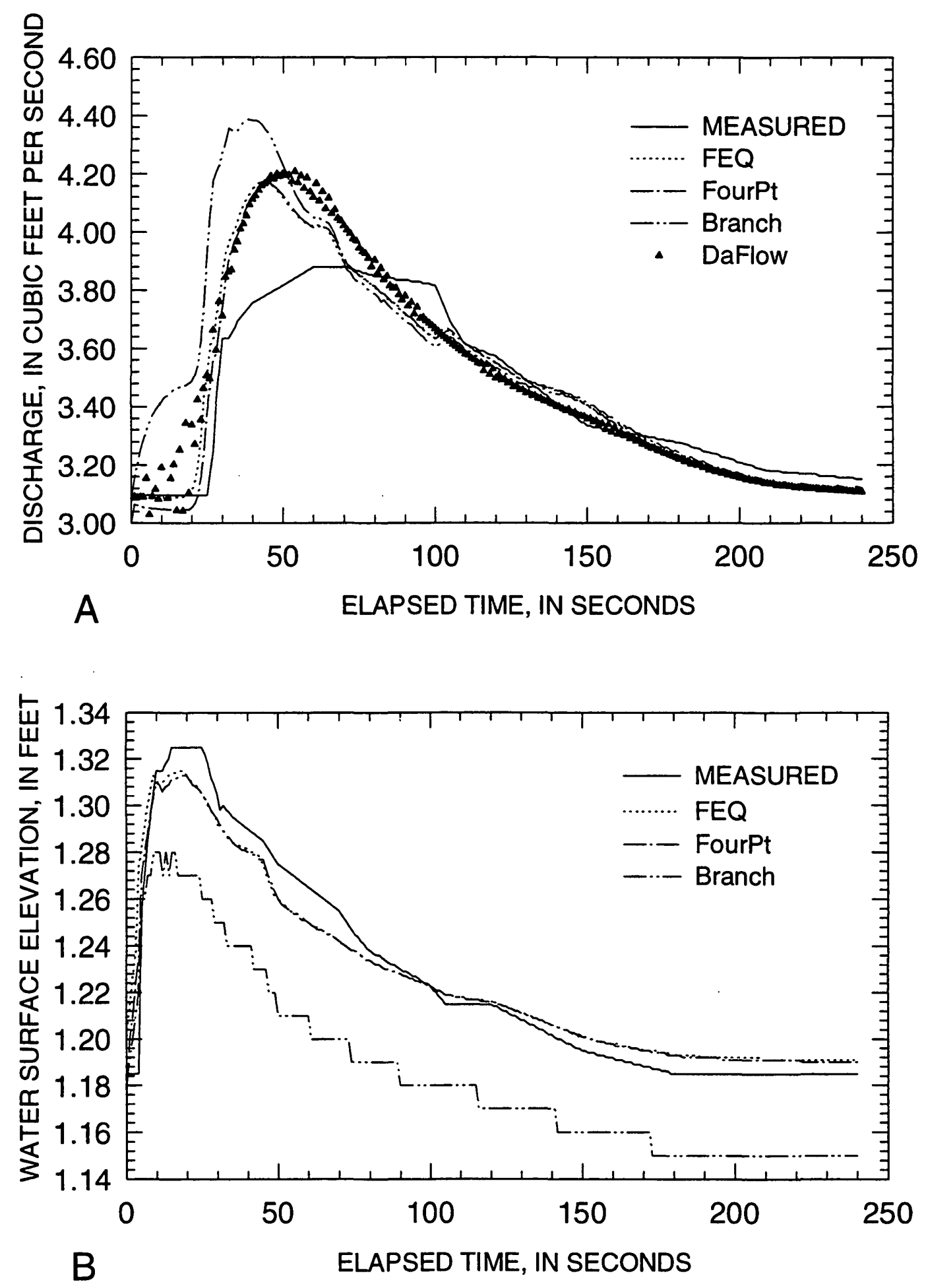

Figure 5. Results of models for U.S. Army Corps of Engineers flume data plotted with measured data at: A) downstream and B) upstream ends of reach for 1-second time step and 5-feet spatial discretization. 


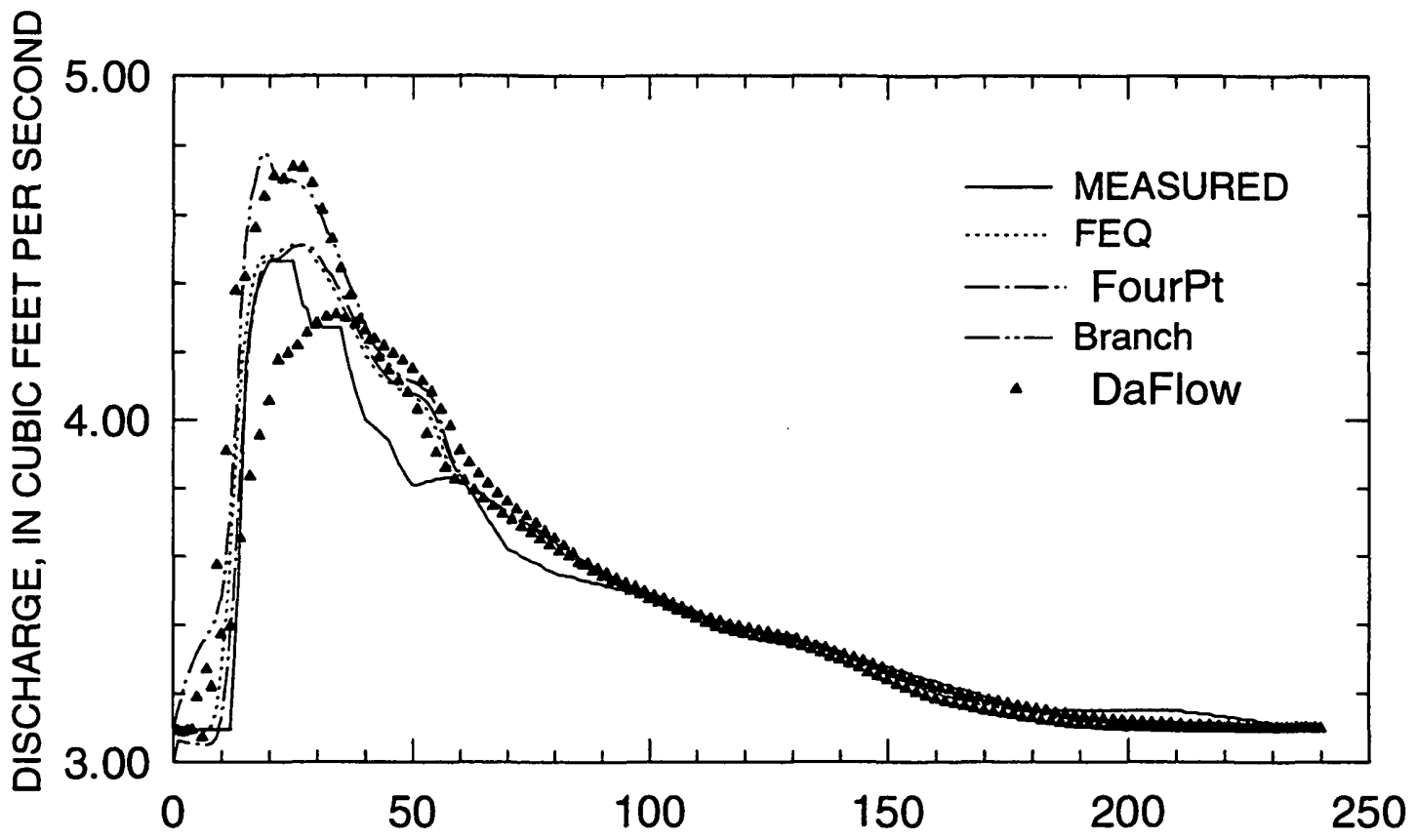

A ELAPSED TIME, IN SECONDS

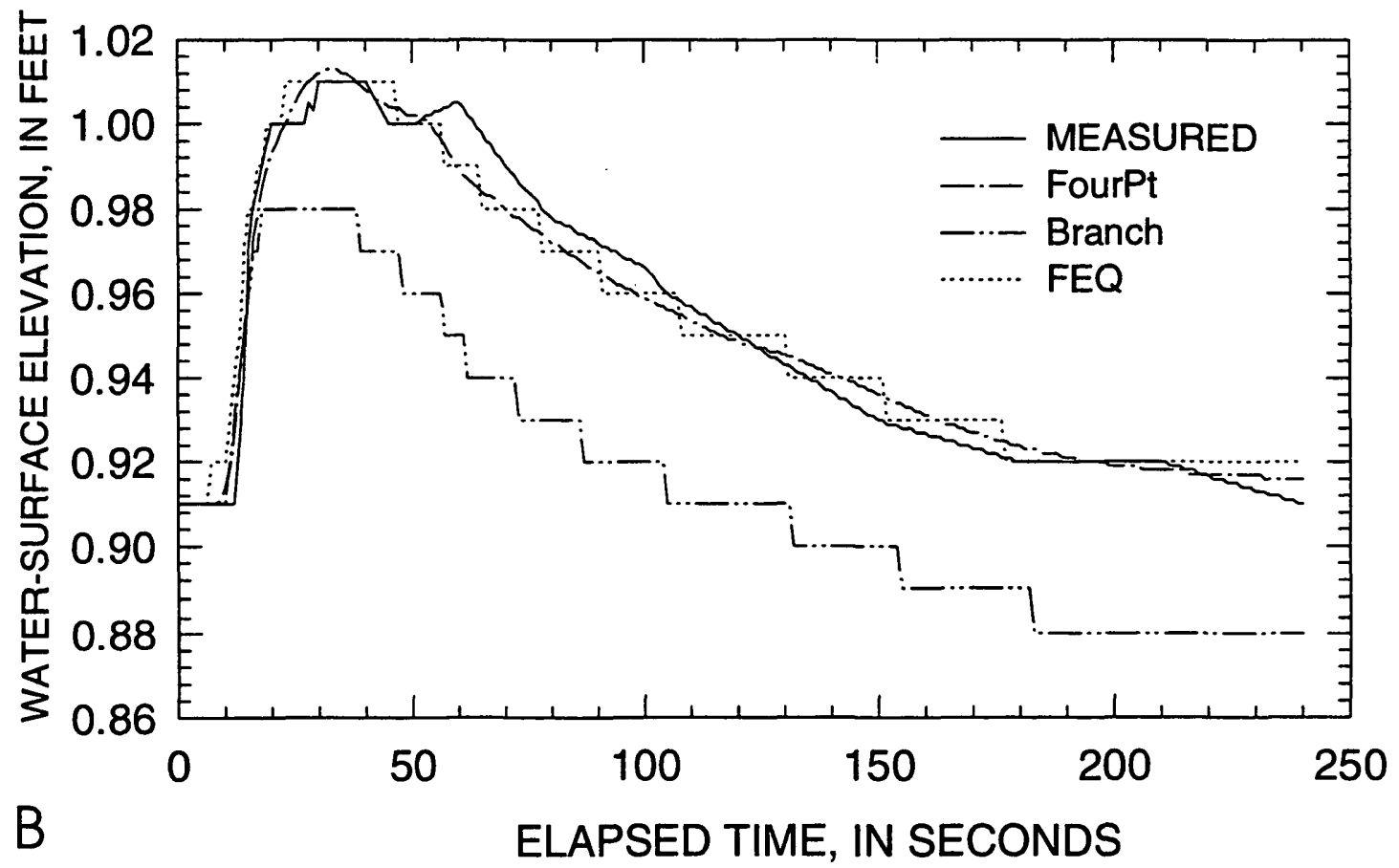

Figure 6. Results of models for U.S. Army Corps of Engineers flume data plotted with measured data at location $70 \mathrm{ft}$ upstream of outflow end; A) discharge comparison, B) stage comparison for 1-second time step and 5-foot spatial discretization. 
Because DaFlow is an explicit model, its stability is limited by the grid discretization and the time-step size. Explicit flow models are conditionally stable and are limited by a Courant condition that states that the sum of the wave and advection velocity cannot exceed the ratio of the space discretization and time step. The 1-second time step and 5-foot space discretization exceeds DaFlow's stability limits producing the oscillations of discharge in the plots (fig. 6A). The four-point implicit models do not show oscillations to the extent that DaFlow does at this space discretization and time step. DaFlow output results contained numerous warnings that problems existed for this result. At a larger space discretization, 25 $\mathrm{ft}$, such oscillations were not evident. The comparison of figures 5 and 6 also illustrates that comparisons of model results at set boundary conditions can overstate a model's performance. $\mathrm{DaFlow}$ oscillations are much larger for the middle location (fig. 6) than for the boundary location (fig. 5).

\section{Sacramento River data results}

Only Branch, FourPt, and FEQ models were run with the Sacramento River Data because DaFlow is not capable of modeling backwater effects. The FEQ model does not normally permit the use of stage boundary conditions at all ends of a network. The original single branch was split into two branches and a dummy branch added to overcome this limitation. Both Branch and FourPt allow a flow simulation to be driven entirely by stage boundary conditions.

Branch, FourPt, and FEQ were run for two hydrographs using a 15-minute time step and three cross sections 5.4 miles apart. Both Branch and FourPt were initially run with just two cross sections because no dummy reach was needed. They were changed to three cross sections to match the number of nodes that were used in the reach by FEQ. Measured crosssection data were available for the channel at the two end cross sections (or nodes).

For the first hydrograph simulated (October 12, 1976), FourPt matched the measured discharge hydrograph closely (fig. 7). Branch and FEQ displayed oscillatory behavior at the beginning of the hydrograph. FEQ showed more oscillatory behavior on start up because of its use of normal-flow conditions as initial conditions (FEQ does not allow the user to set specific initial conditions at each node). After overcoming the large initial error, FEQ matched the peak and most of the hydrograph similar to FourPt. Branch tended to overestimate slightly the flows and FourPt and FEQ tended to underestimate slightly the flows. Time-step iterations for Branch did not always converge within 10 time steps allowed nor when as many as 30 time steps were allowed. Timing of the flows was similar among the tested models and represented the measured timing well after the initial oscillations. It is possible that additional spatial discretization of the reach would have reduced the oscillatory behavior in the solution. However, solutions seemed adequate for model comparison, so no further spatial discretization was attempted.

For the second hydrograph (January 17, 1977), no measured discharges were available (fig. 8). Only a comparison between the models was possible. All of the four-point implicit models had similar timing of the peaks, indicating that the models either have the same or no timing errors. FourPt and Branch computed similarly sized flows. FEQ computed flows that 


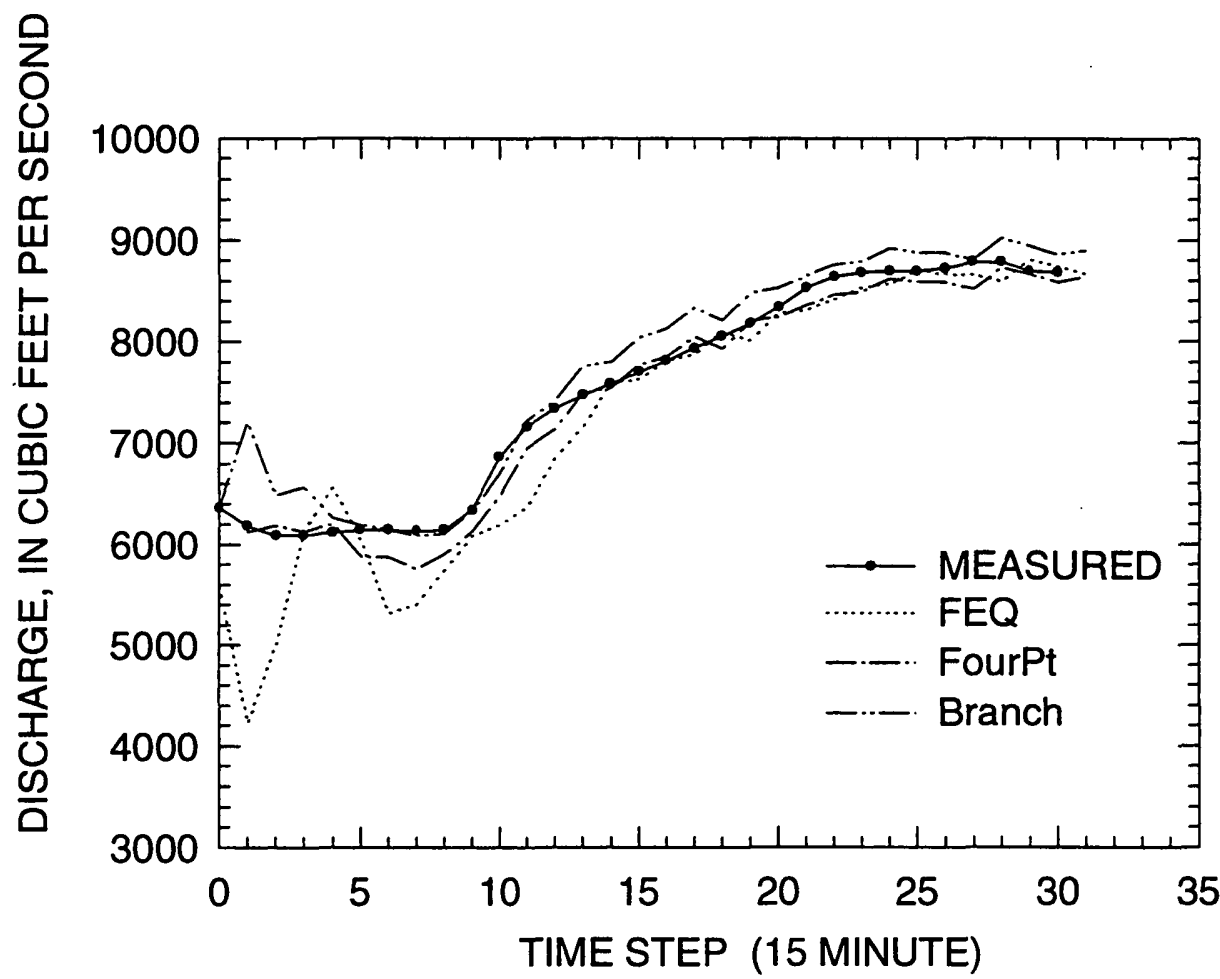

Figure 7. Results of models for Sacramento River for October 12, 1976 data plotted against discharge at downstream end for a 15-minute time step and 28,512-foot spatial discretization.

were slightly lower except at the Sacramento end of the reach, where the lowest computed discharges were one-third smaller than those computed by either FourPt or FEQ. Branch and FourPt had oscillatory behavior during the first steps, probably due to poorly defined initial conditions.

\section{Mass-Conservation Check}

Each model was checked for proper mass or volume conservation because it is important that flow models properly conserve mass. Any errors in mass conservation cumulate in a transport model if the flow model fails to conserve mass. Mass conservation was checked over a time step and for the entire simulation by using model results printed in the output. Simple programs were constructed to compute the check from each program output. Only one run per data set was selected for mass conservation checking.

Absolute errors were computed by a mass balance check over each time step (table 4). The mass balance was computed over a time step from the difference between the change in volumetric storage and the difference in flow volume in and out of the external boundaries. Percent errors were computed by dividing the absolute error by the previous time-step channel 

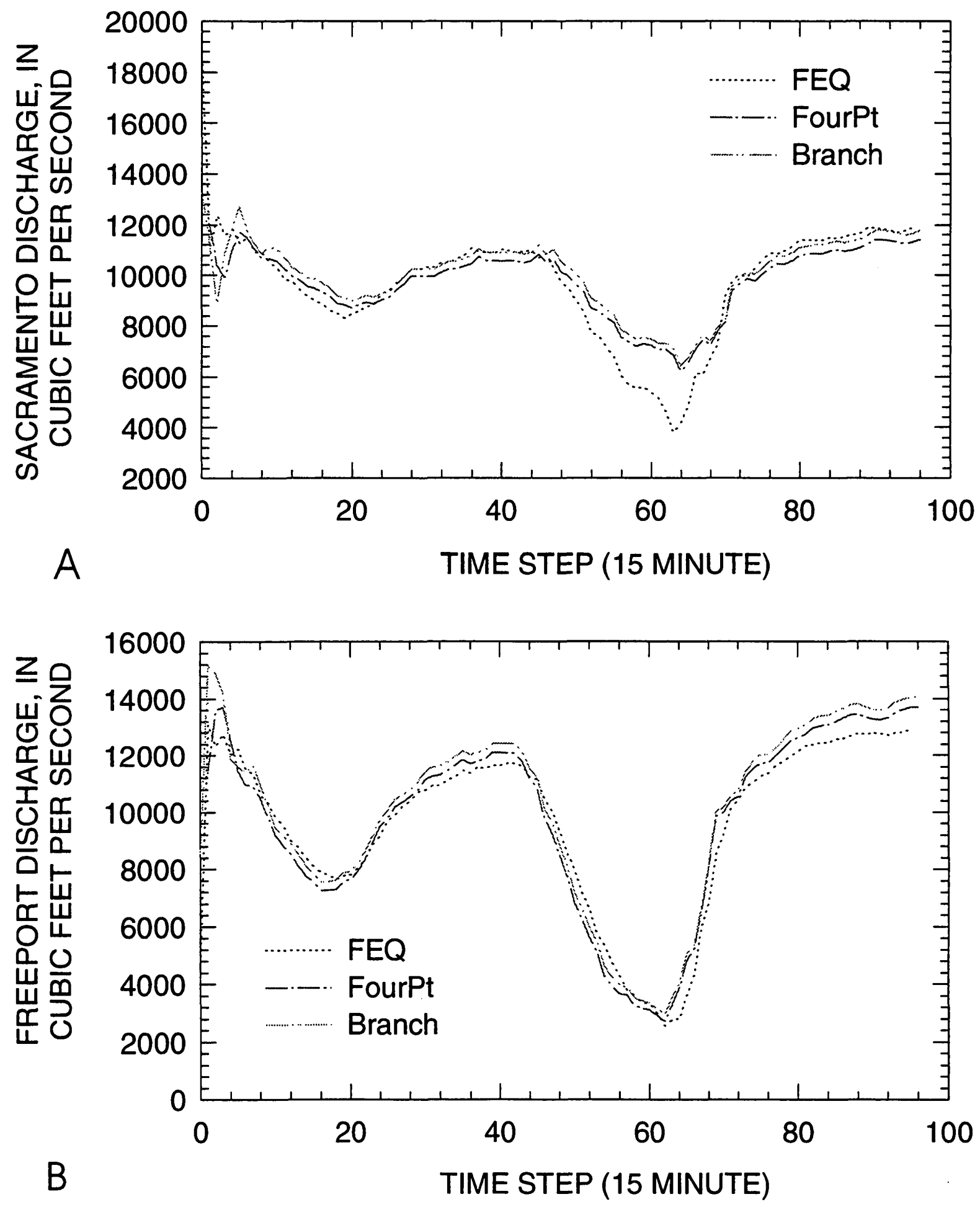

Figure 8. Results of models for Sacramento River hydrograph of January 17, 1977. 
volume and multiplying by one hundred. The statistics presented are the maximum-percent absolute error $(\max )$, the average absolute error per time step (iter), and the percent absolute error for the simulation period (all). Maximum-percent absolute error is the largest error computed for any time step during the simulation. Average absolute error per time step is the sum of the time-step percent absolute errors divided by the total number of time steps in a simulation. The percent absolute error for the simulation period is the change between the initial and final volumetric-storage difference with the difference between the sum of the inflows and the sum of the outflows over the simulation period. Statistics for the COE dambreak data are at a 1-second time step and 5-ft space except for DaFlow, which are shown for a 25 -ft space discretization. For the Treske data, the results are for a 180-second time step and 172.25-ft space discretization. For the Sacramento River data, the results are for a 15minute time step with a 10.8-mile space discretization.

Table 4. Summary statistics of mass conservation absolute errors in percent [max, maximum absolute error for a time step; iter, average absolute error per time step; all, absolute error over the simulation; na, not applicable; COE, Army Corps of Engineers]

\begin{tabular}{|l|c|c|c|c|c|c|c|c|c|}
\hline \multirow{4}{*}{ Model } & \multicolumn{9}{|c|}{ Data Set } \\
\cline { 2 - 11 } & \multicolumn{2}{|c|}{ COE dam break } & \multicolumn{3}{c|}{ Treske } & \multicolumn{3}{c|}{ Sacramento River } \\
\cline { 2 - 11 } & \multicolumn{2}{|c|}{ absolute percent error } & \multicolumn{3}{c|}{ absolute percent error } & \multicolumn{3}{c|}{ absolute percent error } \\
\cline { 2 - 11 } & $\max$ & iter & all & $\max$ & iter & all & $\max$ & iter & all \\
\hline \hline Branch & 0.14 & 0.01 & 0.26 & 6.64 & 0.55 & 7.36 & 0.05 & 0.01 & 0.13 \\
\hline FourPt & .13 & .01 & .05 & 2.46 & .13 & 1.42 & .05 & .02 & .13 \\
\hline FEQ & .08 & .01 & .05 & 1.58 & .21 & .75 & .63 & .12 & .06 \\
\hline DaFlow & .14 & .02 & .28 & .03 & $>.01$ & .26 & na & na & na \\
\hline
\end{tabular}

For most runs, the models conserved mass adequately and errors were not statistically significant (errors $<1 \%$ ). For the four-point implicit models, FEQ had the smallest mass conservation errors for the dam break and Treske data. Branch and FourPt had errors about one-half the size of FEQ for the Sacramento River data. The largest errors for the Treske data were computed for the Branch model; the errors were more than twice as large as the errors for FourPt or FEQ. FourPt also had a fairly large error over the entire simulation for the Treske data. 


\section{PROGRAM MAINTAINABILITY}

Every program requires maintenance. Program code often needs to be changed to reflect new modeling needs, such as redimensioning arrays, and to repair any errors that are discovered. Access to source code is required for program maintenance or improvements. If the program is from outside sources, then it should be in the public domain. Preferably, source code should be written in a programming language that is familiar to the programmers that will be maintaining the source code. Additionally, the source code should be annotated and structured so that it is easy to follow and can be modified easily.

Source codes for all the tested programs are available and written in F77 Fortran. Only the source code for Branch, FourPt, and DaFlow were actually scanned. A small sample of source code for an FEQ utility program, however, was available. All programs have annotated source code that describes the variables used. Three of the models-Branch, FourPt, and DaFlow-were written and are maintained by the USGS. FEQ was written and is currently maintained by an engineering consultant. Maintenance and modification of FEQ by USGS personnel could possibly result in competing versions of the program-a consultant version and a USGS version.

All programs have annotated source code. FourPt was written using a programming style that employs FORTRAN modules (DeLong and others, 1992) and data encapsulation. Data encapsulation is a feature that is employed in object-oriented programs. This programming style allows easy inclusion of new functions into the code with minimal impact on most of the source. The other programs are written in a traditional F77 style, without attempts at data encapsulation. The ease or difficulty of adding new features to these programs will likely depend on the feature being added. Changes to these programs may or may not significantly impact the structure of the original code.

\section{EASE OF MODEL USE}

Overall ease of model use is a function of how difficult it is to perform the tasks required to prepare, run, and analyze a flow simulation. Unfortunately, how easy a model is to run is a subjective judgment that is influenced by a person's prior modeling experience and educational background. Every modeler, regardless of experience, however, must perform the same tasks: assemble the appropriate data, prepare the input file or files for the model, alter the time-step size, change the spatial discretization, add new cross sections, change the roughness coefficients, set or change the boundary conditions, and analyze the results. The ease with which each of these modeling tasks can be done with each model is summarized.

All models tested require the modeler to schematize carefully the reach of interest and provide initial flow conditions. The amount of cross-section data, boundary data, and initial conditions required to run the models, however, varied between the four-point implicit models and DaFlow. The four-point implicit models require detailed cross-section measurements at sufficient locations along the reach to describe adequately the reach geometry and estimates of roughness coefficients. Two boundary conditions are required by these models for a simple branch. Branch requires initial conditions to be specified at each cross section or 
node. FEQ uses step-backwater computations to compute initial conditions from a discharge and stage specified for the branch. This can be a disadvantage for streams, especially those that are affected by tides, where step-backwater calculations will result in inappropriate initial conditions. FourPt will compute or interpolate initial conditions from stages and/or discharges specified for a branch or allow specification of initial conditions at each node. In contrast with the four-point implicit models, DaFlow has fewer data requirements. DaFlow requires representative areas and widths at two flow rates and zero flow, and either lagtimes for two flow events or roughness values at two flow depths. DaFlow requires only one boundary condition to be specified per two open boundaries and an initial discharge at each node.

All models can use several different files to supply the needed input for the programs. Branch, FEQ, and DaFlow use fixed-field format input files. FourPt uses free-field input files that are usually annotated with text that identifies the variables. DaFlow has a preprocessing program that builds the input file through user queries and a boundary-condition file. Except for DaFlow, all the input files used in the testing were prepared with a text editor. Fixed field formats are typically harder to edit with text editors than free-field formats because of the precise spacing required by fixed fields. The DaFlow and FourPt files were found to be easy to modify in a text editor. The Branch files were somewhat harder to modify because of the tightly packed fixed-field input fields. The FEQ input files were the largest and had the most complicated structure. The complicated structure of FEQ files is due in part to the FEQ having the largest number of different record types of the models tested. The large number of record types and associated lengthy documentation make FEQ input files prone to input mistakes by new users, including users with previous $1-D$ unsteady modeling experience.

The procedure to alter the time-step size in all of the four-point implicit models is similar. Only one parameter is necessary to change time-step size in these models. Branch uses parabolic interpolation to compute intermediate time-step data from the input boundary conditions. FourPt and FEQ use linear interpolation. DaFlow requires the boundary condition data to be altered to fit the time step used in the model when the time step is changed.

All models tested allowed different spatial discretizations to be used. Often spatial discretization needs to be reduced either to check convergence of the model or to allow the model to find a solution. For the FourPt model one parameter specifying the length between nodes (cross sections) is changed for each branch to alter the spatial discretization. The preprocessor program for DaFlow needs to be rerun to change the spatial discretization. This results in rebuilding the entire input file. Branch requires that tabulated properties be available at each computational node. This requires the modeler to run a hydraulic properties program, such as CGAP, to provide the tables at the new nodes, regardless of whether the geometry changes in the reach. For FEQ spatial discretization is changed by indicating the number of nodes (cross sections) to add between existing cross sections, specifying the location of each intepolated or propagated cross section in the input file, or by rerunning the hydraulic properties program. The FEQUTL program will interpolate hydraulic property tables for locations between existing cross sections.

All models tested allowed additional measured cross sections to be added. Frequently, modelers add cross sections to refine the description of the reach geometry. The four-point 
implicit models require that the modeler run a hydraulic properties program to provide the tables at the new cross sections. Similarly, DaFlow's preprocessor program needs to be rerun to add new cross sections.

Roughness coefficients are often changed during model calibration so that the results better match measured data. Branch can be the simplest of the models tested to change roughness coefficients if the roughness coefficients can be specified by a quadratic equation that is a function of a selected flow parameter: temperature, depth, discharge, Froude number, Reynolds number, or water-surface elevation. In Branch, the roughness coefficients can be entered with the initial condition data for each cross section and can be easily edited. No hydraulic properties program needs to be run. However, if roughness coefficients are included in the cross-sectional geometry data records, each entry in the cross-section data will need to be edited. For FEQ and FourPt, the hydraulic-properties program that provides geometry tables to the model needs to be run after roughness values are edited. For DaFlow, the CEL program needs to be rerun.

Boundary conditions can be changed by substituting file names in the program control parameters in the FEQ, FourPt, and Branch models. Boundary files are easiest to prepare for Branch. FEQ boundary-condition files are similar to Branch but require time flags for each value. These boundary-condition files are organized by boundary node into a separate group or file. As previously noted, FEQ requires multiple branches for stage-stage boundary conditions to run. DaFlow and FourPt require more effort to include changed boundary conditions. FourPt requires upstream and downstream boundary conditions for a branch to be interleaved into one file. DaFlow requires that the preprocessor program be rerun so that the new boundary conditions are included in the input file.

\section{SUMMARY OF MODELS CAPABILITIES}

Three of the models tested, Branch, FourPt, and FEQ, are similar in modeling capabilities and the numerical technique used. The DaFlow model is the only explicit model tested and has more limited capabilities than the other three models. The various computational features of the models tested are summarized in table 5 .

Most of the features listed in table 5 have been presented previously in the paper. However, two models have features that have not been discussed. Branch can be linked with the USGS groundwater model, MODFLOW (Swain and Wexler, 1993). FEQ can automatically reduce the time-step size when the equations become more difficult to solve. FEQ also is able to hold the boundary conditions fixed in time, which permits the model to adjust (or wind up) to a near steady-state condition before actual changes in boundary conditions are applied.

\section{SUMMARY}

All the models tested have reasonable results with the appropriate data sets and could be successfully used to meet many flow modeling needs. The models that are capable of 
Table 5. Summary of one-dimensional unsteady flow models features $[B$, top width; $A$, area; $D$, depth; $K$, conveyance; $P$, wetted perimeter; $Y$, stage; $Q$, discharge; $\eta$, psuedo-roughness; $S_{1}$, friction slope; $\beta$, momentum coefficient; $M_{q}$, discharge weighted sinousity; $M_{a}$, area weighted sinousity]

\begin{tabular}{|c|c|c|c|c|}
\hline & \multicolumn{4}{|c|}{ Models } \\
\hline & DaFlow & Branch & FourPt & FEQ \\
\hline Equation used & $\begin{array}{l}\text { diffusion-analogy } \\
\text { (kinematic wave) }\end{array}$ & $\begin{array}{l}\text { full dynamic, } \\
\text { including wind }\end{array}$ & $\begin{array}{l}\text { full dynamic, } \\
\text { including density }\end{array}$ & $\begin{array}{l}\text { full dynamic, } \\
\text { including wind }\end{array}$ \\
\hline Solution type & explicit & 4 point implicit & 4 point implicit & 4 point implicit \\
\hline Nodal Data: supplied by & functions of $Q$ & tabled by y & tabled by $y$ & tabled by $y$ \\
\hline Nodal Data: input data & $\mathrm{B}, \mathrm{A}, \mathrm{D}$ & $\mathrm{B}, \mathrm{A}, \eta$ & $\mathrm{B}, \mathrm{A}, \mathrm{K}, \boldsymbol{\beta}, \mathrm{P}, \mathrm{M}_{\mathbf{q}}, \mathrm{M}_{\mathrm{a}}$ & $\mathrm{B}, \mathrm{A}, \mathrm{K}, \boldsymbol{\beta}, \mathrm{P}, \mathrm{M}_{\mathrm{q}}, \mathrm{M}_{\mathrm{a}}$ \\
\hline Nodal Data: output data & Q,A,B & $\mathrm{Y}, \mathrm{Q}$ & $\mathrm{Y}, \mathrm{Q}$ & $\mathrm{Y}, \mathrm{Q}$ \\
\hline Boundary Conditions & Q & $\mathrm{Y}, \mathrm{Q}, \mathrm{S}_{\mathrm{f}}$ & $\mathrm{Y}, \mathrm{Q}$ & $Y, Q$ required \\
\hline Initial Conditions & 1) at each node & 1) at each node & $\begin{array}{l}\text { 1) at each node } \\
\text { 2) normal depth } \\
\text { 3) steady flow } \\
\text { 4) interpolated }\end{array}$ & 1) steady flow \\
\hline Hydraulic Controls & none & tables & tables \& routines & tables \& functions \\
\hline Groundwater link & in development ${ }^{t}$ & yes $^{1}$ & no & no \\
\hline Auto grid refine & no & no & yes & yes \\
\hline Time-step refine & no & yes & yes & yes $^{2}$ \\
\hline
\end{tabular}

1 provides links to MODFLOW, USGS groundwater model

2 can automatically refine time step to improve solution and hold boundary conditions constant for model spin up. 
simulating the effects of hydraulic structures (FEQ, FourPt, Branch) such as weirs, gates, bridges and culverts, usually use information that is either actual data (such as a rating) or results from a steady state 1-D model. Only FEQ can include some types of structures directly. Two of the models, FEQ and FourPt, had more robust solutions than the other models tested.

The DaFlow model was the easiest to use of the models tested and reasonably simulated two of the data sets. It is limited, however, by the equations solved. Solution results do not include stages. Hydraulic depth can be calculated from the simulated area and top width. Stage can be computed if tables of area and stage are available. The DaFlow model cannot simulate backwater affected reaches or account for rapid variations in cross-section top width. Because of these limitations, it cannot be used at slope-station sites for continuous discharge measurements.

The Branch model showed some possible numerical problems in the results computed for the COE flume and Treske flume data. The model produced an unrealistic rise in the discharge curve prior to the arrival of the flood peak for the COE flume data. The Branch model had problems when the flow entered or exited the overbank areas, in part because of the direct computation of simple conveyances for the Treske flume data. Branch had, relative to the other models, larger mass conservation errors, especially for the Treske data. The computational efficiency of Branch is limited by its matrix-solution technique, especially for large stream systems.

FEQ simulation results for the data sets were similar to most of the four-point implicit models. FEQ does not model stage-stage boundary conditions as simply as the other fourpoint implicit models. To use stage-stage boundary conditions, a dummy reach with a flow boundary condition must be included in the stream system. FEQ modeled the tidally affected Sacramento River similar to the other four-point implicit models but oscillated in the early stages of the simulation of the October 12, 1976 hydrograph because of poor fit of the initial conditions. FEQ had the largest mass conservation errors for the stage-stage boundary condition data (Sacramento River data). FEQ performed well on the other data sets, with the smallest mass conservation errors of the four-point implicit models. FEQ has large complex input files.

The FourPt model simulated all of the data sets closely with reasonable mass-conservation errors and did not display unexpected numerical problems. Results were not statistically significantly different from the FEQ results. Stage-stage boundary conditions can be applied as simple boundary conditions with the same effort as stage-discharge boundary conditions. The source code should be easy to modify to meet changing needs because of its data encapsulation programming style.

\section{REFERENCES}

Cunge, J.A., Holly, Jr., F.M. and Verwey, A., 1980, Practical aspects of computational river hydraulics. Marshfield, MA: Pitman Publishing, Inc.

Davidian, J., 1984, Computation of water-surface profiles in open channels: U.S. Geological Survey Techniques of Water-Resources Investigations, Book 3, Chapter A15, 48p. 
DeLong, L.L., 1986, Extension of the unsteady one-dimensional open-channel flow equations for flow simulation in meandering channels with flood plains: In S. Subitzky (ED.), Selected Papers in the Hydrologic Sciences, pp. 101-105. U.S. Geological Survey WaterSupply Paper 2290.

DeLong, L.L., Thompson D.B. , and Fulford, J.M., 1992, Data encapsulation using Fortran 77 modules: Fortran Forum 11930, 11-19.

DeLong, L.L., Thompson, D.B. and Lee, J.K., 1997, The computer program FourPt (version 95.01)- a model for simulating one-dimensional, unsteady, open-channel flow: U.S. Geological Survey Water Resources Investigations Report 97-4016, 69p.

Franz, D.D., and Ishii, A., 1997, User's guide for the Full-Equations (FEQ) Model of onedimensional, unsteady, open-channel flow. On file with U.S. Geological Survey, at Urbana, IL 61801.

Franz, D.D., and Melching, C.S., 1997a, Full Equations (FEQ) Model for the solution of the full, dynamic equations of motion for one-dimensional unsteady flow in open channels and through control structures: U.S. Geological Survey Water Resources Investigations Report 96-4240, 258p.

-1997b, Full Equations Utilities (FEQUTL) Model for the approximation of hydraulic characteristics of open channels and control structures during unsteady flow: U.S. Geological Survey Water Resources Investigations Report 97-4037, 205p.

Fulford, J.M., 1993, User's guide to hydraulic information exchange program: A computer program for hydraulic properties computations. On file with U.S. Geological Survey, at Stennis Space Center, MS 39529.

Fulford, J.M. 1995, User's guide to the culvert analysis program: U.S. Geological Survey, Open-File Report 95-137, 69p.

Leopold, Luna B., Wolman, M.G., and Miller, J.P., 1964, Fluvial processes in geomorphology: San Francisco, CA: W.H. Freeman and Company.

Press, William H., Flannery, B.P., Teukolsky, S.A., and Vetterling, W.T., 1986, Numerical recipes, the art of scientific computing: New York, N.Y.: Cambridge University Press.

Jobson, H.E., 1989, User's manual for an open-channel stream flow model based on the diffusion analogy: U.S. Geological Survey Water-Resources Investigations Report, 894133, 73p.

Regan, R.S., 1985, A computer program for analyzing channel geometry: U.S. Geological Survey Water-Resources Investigations Report 85-4335, 49p.

Regan, R.S. and Schaffranek, 1992, unpublished notes distributed with program by HASS, Summary of enhancements and additions. Branch-Network (BRANCH) Dynamic Flow Models

Sanders, Jr., C.L., 1995, The use of three-parameter rating table lookup programs, rdrat and parm3, in hydraulic flow models: U.S. Geological Survey Open File Report 95-4090, $17 \mathrm{p}$.

Shearman, J.O., 1990, User's manual for WSPRO--A computer model for water surface profile computations: Federal Highway Administration, IP-89-027, 112p.

Schaffranek, R.W., Baltzer, R.A., and Goldberg, D.E., 1981, A model for simulation of flow in singular and interconnected channels: Techniques of Water-Resources Investigations of the U.S. Geological Survey, Chapter C3, Book 7, 110p. 
Schmidgall, T. and Strange, November 1961, Floods resulting from suddenly breached dams conditions of high resistance: Miscellaneous Paper No. 2-374, Report 2, U.S. Army Corps of Engineers Waterways Experiment Station.

Swain, E.D. and Wexler, E.J., 1993, A coupled surface-water and ground-water model for simulation of stream-aquifer interaction: U.S. Geological Survey Open-File Report 92$138,162 \mathrm{p}$. 